\title{
DESIGN PARA A EXPERIÊNCIA: atributos e possibilidades de atuação
}

\author{
Maria Regina Álvares Dias \\ Escola de Design - Universidade do Estado de Minas Gerais - UEMG \\ regina.alvares@gmail.com \\ Ana Carolina Ribeiro \\ Escola de Design - Universidade do Estado de Minas Gerais - UEMG \\ anacarolaribeiro@gmail.com
}

\begin{abstract}
Resumo: o propósito desse trabalho é buscar entender quais as novas abordagens e possibilidades do design dentro do contexto de construção de cenários que sejam mais experienciais, do ponto de vista existencial e humano, procurando atribuir sentido as ações humanas coletivas e individuais. Pretende-se com essa pesquisa apoiar, inspirar novos estudos e incentivar a criação de projetos que não se restrinjam a objetos, lugares ou serviços, mas, sobretudo, ao desenho de contextos ambientais e culturais aptos ao florescimento de experiências humanas singulares e significativas. A pesquisa iniciou-se em Belo Horizonte e se estendeu até a Índia, na cidade de Bangalore. Deste modo, a pesquisa bibliográfica foi realizada no Brasil e a entrevistas e análises foram realizadas na Índia. O resultado final mostrou que essa nova abordagem chamada "design para a experiência" inaugura novas possibilidades de atuação no campo do design, propondo a construção de uma abordagem mais humana e mais preenchida de significados e valores.
\end{abstract}

Palavras-chave: experience design, experiência, contemporaneidade, subjetividade, ressignificação.

Abstract: we live in a world plagued by an increasing sequence of events, however, the experiences are gradually being abandoned. So the effort of this work is to seek to understand what new approaches and possibilities of design within the context of building scenarios that are more experiential, existential in the human aspect, looking ascribe meaning to the individual and collective human actions. The aim of this research is inspire new studies and encourage the creation of projects that are not limited to objects, places or services, but especially the design of the contexts ables to flowering significant human experiences and environmental and cultural contexts. The research started in Belo Horizonte at the University of Minas Gerais (UEMG) at the School of Design and extended to India, in Bangalore city. Thus, the literature search was performed in Brazil and interviews and analyzes were performed in India. The final result showed that this new 
approach called " experience design " opens new possibilities for action in the field of design, proposing the construction of a more human and filled approach of meanings and values.

Keywords: experience design, experience, contemporary, subjectivity, resignification.

\section{DESIGN PARA A EXPERIÊNCIA}

O mundo contemporâneo tem sido marcado por uma série de acontecimentos e eventos que atingem cada vez mais um número maior de pessoas. Contudo, essas ocorrências têm tomado uma dimensão superficial e de caráter corriqueiro. Walter Benjamin (1987), no século passado, já observava a pobreza de experiências que caracteriza o nosso mundo, na visão desse autor vivemos em um mundo no qual nunca se passaram tantas coisas, mas a experiência é cada vez mais rara (BONDÍA, 2002).

Segundo Moresco (2011) no contexto atual, onde consumidores valorizam cada vez mais as experiências, é necessário compreender os diferentes desdobramentos e aplicações deste conceito. Experiência de consumo, venda de experiências, design de experiências são muitas as formas sob as quais encontramos o conceito de experiência diluído na sociedade atual. Porém, é preciso dar um passo atrás para compreender o que significa, de fato, experiência. Ou, ainda, quais os possíveis conceitos de experiência que podemos utilizar no nosso dia-a-dia. Isto porque antes de falar de áreas de conhecimento ou disciplinas relacionadas à experiência, é preciso saber o que o conceito significa (MORESCO, 2011).

Experiência é "ação ou efeito de experimentar; conhecimento adquirido pela prática da observação ou exercício: ter experiência. Ensaios, tentativas para verificar ou demonstrar qualquer coisa: fazer uma experiência" (FERREIRA, 1986). Essa definição possui um aspecto significativo para o entendimento do que é experiência, "conhecimento adquirido pela prática", portanto seria inadequado tratar de uma experiência sem movimento e/ou sem qualquer outro tipo de prática que nos leve a refletir ou criar sentido sobre determinada ação.

No livro "Cantos de experiência - Variaciones modernas sobre un tema universal" de Martin Jay, são apontados diferentes autores como Walter Benjamin, Michel Foucault e Theodor Adorno para conceituar experiência. Nesse livro é possível encontrar algumas importantes definições. Para Jay, "a experiência é o ponto de intersecção entre a subjetividade de um indivíduo e a variedade de ambientes externos na qual está inserido" (JAY, 2009).

Portanto, o ato de projetar experiências deve funcionar como uma conexão entre as expectativas diversas de um indivíduo e o que lhe é apresentado através de seus sentidos, que são a porta de entrada para o acesso ao mundo exterior.

Jay (2009) explica que "a experiência implica necessariamente na existência de outro agente - seja uma pessoa ou um ambiente, por exemplo - e que deve sempre provocar uma mudança, um novo acontecimento". Relacionando essa definição acima como as disciplinas modernas que têm como base a experiência, como o Design de Experiência, perceberemos que há diversas conexões entre os conceitos.

De acordo com Moresco (2011) no Design de Experiência (...) os ambientes físicos, os serviços ofertados, os produtos digitais - ou qualquer que seja o meio podem e devem ser projetados para despertar emoções capazes de estabelecer um 
vínculo entre consumidores e marca e, portanto, representam uma forma de provocar mudança (MORESCO, 2011).

Na visão de Nardelli (2007) o design para a experiência atua sobre o dia-a-dia das pessoas, abrangendo desde os aspectos culturais e contextuais que envolvem os indivíduos até as suas formas de relacionar-se com os objetos. "Não só trata de enxergar os objetos como instrumentos facilitadores na execução das tarefas do dia-adia, mas pensar as relações entre objetos e indivíduos de maneira mais ampla para além da questão do uso, cuidando de outras instâncias e formas de apropriação possíveis" (NARDELLI, 2007, p. 99).

Assim, projetar uma experiência significa planejar situações e predispor condições. Por esse motivo é mais adequado dizer "design para a experiência" ao invés de "design da experiência". Essa abordagem considera que a experiência surge a partir do trabalho do designer de maneira indireta, no momento em que este projeta e cria condições propícias para que ela se realize (NARDELLI, 2007).

A experiência pode ter caráter transformador numa dada situação, sendo sempre um fato extremamente pessoal e, portanto não programável. Entretanto, é possível predispor-lhe condições de modo a potencializar as possibilidades para que ela se realize (NARDELLI, 2007, p. 100). A criação de condições favoráveis não se restringe ao projeto de um objeto, lugar ou serviço, mas, sobretudo, um contexto ambiental e cultural apto ao florescimento de experiências humanas singulares e significativas.

Segundo Benjamin (1987) a experiência se configura como uma relação mais densa que a vivência, pois é composta por mensagens de limites menos rígidos e abertas a interpretações variadas, possibilitando o desenrolar de narrativas diversas. Esse caráter particular e potencialmente diverso das experiências agrega os indivíduos uma sensação de ativação e de integração constante com o mundo externo e com outras pessoas (NARDELLI, 2007).

Esse caráter particular e potencialmente diverso das experiências citado anteriormente, é abordado por Cardoso (2008) em sua obra "Uma introdução à história do design", segundo o autor "todos os temas e tratamentos se misturam sem nenhum compromisso com a chamada realidade, mas apenas uma preocupação crescente com o realismo da experiência representada" (CARDOSO, 2008, p. 237).

Deste modo, para compreender os atributos e possibilidades do projeto para a experiência, é preciso ir além dos fatores de pertencimento e relação única e exclusiva dessa temática com design. Portanto, "pensar o design para a experiência significa pensar o todo que compõe o sistema que culmina na experiência na qual os objetos e o caráter mediador e de interação que possuem são apenas alguns aspectos a serem projetados pelo designer" (NARDELLI, 2007, p. 101).

Diante desse contexto novos parâmetros têm sido criados, na busca pela readequação de antigos paradigmas. Nessa conjuntura de imprecisões e complexidade desponta-se a relevância, sobretudo nas escolas superiores, em "definir e situar o design nos cenários da educação e da sociedade" (SCHNEIDER, 2010, p. 193) a fim de compreender o atual cenário dessa atividade no contexto mundial.

Nas últimas décadas nota-se que novos métodos e iniciativas foram surgindo em velocidades maiores, adquirindo dimensões cada vez maiores e mais expressivas. Além disso, como o passar do tempo, muitos estudos evidenciaram que "ser designer é, radical e irrevogavelmente, algo que muda constantemente" (PRESS e COOPER, 
2009, p. 18). Assim, novas abordagens emergem, na tentativa de alinhar o design ao comportamento social contemporâneo e suas novas implicações.

Diante dessa conjuntura e pensando no contexto do design, diversas questões e debates despontam-se, na busca de compreender aspectos como: existem atributos específicos para que um projeto de design seja considerado um projeto para a experiência? Quais seriam as estratégias e ferramentas de design para valorar $e$ ressignificar as experiências humanas a fim de contribuir para a construção de um sujeito mais criativo, autônomo e reflexivo?

O esforço desse estudo é buscar entender as possibilidades do design dentro do contexto de construção de cenários que sejam mais experienciais, do ponto de vista existencial e estético, procurando atribuir sentido as ações humanas coletivas e individuais.

As ideias sintetizadas neste artigo são parte de uma pesquisa de conclusão de curso de graduação em Design de Produto com o propósito de estudar e identificar os atributos e possibilidades do design para experiência.

\section{MÉTODOS E TÉCNICAS}

A pesquisa apresentada tem caráter exploratório, segundo Cintra (1982) que consiste em uma caracterização inicial do problema, sua classificação e de sua definição. Pesquisas dessa natureza proporcionam maior familiaridade com 0 problema, através do levantamento bibliográfico seguido de entrevistas, ou pesquisa bibliográfica seguido de estudo de caso. O levantamento bibliográfico apoiou-se em consultas a livros, revistas especializadas, e a internet (publicações on-line, periódicos disponibilizados, anais de eventos e sites institucionais).

Quanto à forma de abordagem das entrevistas, foi empregada a formulação de questões semi-abertas, de modo que o entrevistado pudesse discorrer à vontade em suas respostas. Por se tratar de um estudo qualitativo, os métodos de análise dos dados foram a categorização dos termos adotados pelos participantes e a análise do discurso. Os dados obtidos foram analisados indutivamente, uma vez que a interpretação das informações obtidas e a atribuição de significados foram consideradas como mais relevantes tendo em vista o objetivo da pesquisa.

\subsection{As entrevistas}

Antes de partir para a descrição do processo das entrevistas, se faz necessário entender para qual contexto os procedimentos foram desenhados. Portanto entendese que cada contexto de pesquisa requer um procedimento metodológico particular e direcionado ao objetivo de cada trabalho.

Essa pesquisa iniciou-se em Belo Horizonte e se estendeu até a Índia, na cidade de Bangalore. Deste modo, a pesquisa bibliográfica foi realizada no Brasil e a entrevistas e análises foram realizadas na Índia. A escolha dessa estratégia de pesquisa foi tomada a fim de unir interesses profissionais com interesses acadêmicos.

De acordo com o Ministério das Relações Exteriores do Brasil a Índia é atualmente um dos cinco países com maior expansão do PIB mundial, os intitulados "Building Better Global Economic BRICs" (BRICS - Brasil, Rússia, Índia, China e África do Sul). Diante desse cenário, o design na Índia tem ganhado cada vez mais força, experimentando novas metodologias e buscado soluções singulares para novos projetos. 
No entanto, apesar de muitos avanços é possível perceber que a influência externa dos países conhecidos como desenvolvidos (EUA e países europeus) ainda é forte. Portanto, em muitos casos os padrões adotados têm com referência parâmetros internacionais de design que pouco se aplicam a realidade nacional. Em decorrência desse aspecto alguns profissionais têm buscado novos caminhos e tentado quebrar paradigmas através do uso de novas abordagens de design.

\subsection{Amostragem}

A identificação dos profissionais para participar no estudo teve como ponto de partida a participação desses profissionais em projetos na área do Experience Design. A escolha por pessoas, e não empresas foi embasada no objetivo geral desse estudo que "é compreender e identificar quais os elementos que constituem o design para a experiência e verificar as possibilidades de atuação do design nesse contexto". Desse modo, para compreender, identificar e verificar possibilidades de atuação julgou-se mais adequado conversar com profissionais e através deles buscar perceber como essa dinâmica ocorre de fato.

O processo de identificar pessoas que potencialmente poderiam ter alguma experiência nessa área se deu através de conversas com outros designers em diferentes contextos (workshops, palestras, treinamentos, reuniões de trabalho, entre outros) na busca de tentar encontrar indicações de pessoas com o perfil desejado.

Após esse processo de indicações, uma lista de pessoas potencialmente envolvidas com o tema foi elaborada contendo nome e endereço eletrônico. Em seguida essas pessoas foram contatadas e receberam uma explicação prévia do que estava sendo investigado e porquê.

A partir daí foram enviados os questionários através de uma plataforma on-line de pesquisa, na qual à medida que o entrevistado preenche os campos de resposta, o pesquisador tem acesso imediato a esses dados. Essa ferramenta foi importante no processo, pois devido às circunstâncias do lugar e do cronograma da pesquisa, em razão do escasso tempo, evitando assim deslocamento e o tempo na transcrição das entrevistas.

Um dos propósitos das entrevistas on-line seria selecionar com maior facilidade pessoas de diferentes nacionalidades de oriundas de diferentes regiões da Índia. Essa diversidade agregou significativo valor ao resultado obtido, pois tornou possível perceber visões de pessoas com diferentes bagagens culturais e experiências profissionais/pessoais distintas como pode ser verificado no Quadro 1.

Quadro 1 - Identificação dos entrevistados, país e profissão

\begin{tabular}{lll}
\hline Nome & País/cidade de origem & Profissão \\
\hline Entrevistado 1 & Índia, Bangalore & Designer Director \\
\hline Entrevistado 2 & Inglaterra, Newcastle & Designer \\
\hline Entrevistado 3 & Índia, Mumbai & Communication Designer \\
\hline Entrevistado 4 & Espanha, Basque & Product Designer and Engineer \\
\hline Entrevistado 5 & Índia, Pattukkottai & Design Consultant \\
\hline Entrevistado 6 & Índia, Kasol & Lead User Experience Designer \\
\hline
\end{tabular}

Fonte: Elaborado pelo autor, com base na pesquisa realizada (2012) 
Esses profissionais tem se deslocado para Bangalore, capital e a maior cidade do estado de Karnataka no sul da Índia e conhecida como o Vale do Silício indiano. 0 crescente desenvolvimento de Bangalore tem chamado atenção especialmente desses entrevistados que estão procurando entender como o design tem funcionado em países como a Índia que tem dado saltos quânticos de crescimento econômico, e diante desse cenário como buscar novos caminhos para lidar com essas mudanças.

Nesse contexto, o Experience Design tem sido tratado como um diferencial e uma saída para as diversas mudanças de comportamento e consumo dos usuários.

\section{DISCUSSÃO DOS RESULTADOS}

Foram realizadas sete questões, além do perfil dos participantes com os dados pessoais de cada entrevistado (país, cidade, nome, email, profissão, etc.). A pergunta acerca do país e da cidade de origem mostrou que a maior parte dos entrevistados, conforme dados do Quadro 1, eram indianos, porém de diferentes regiões da Índia, e os demais eram da Inglaterra e da Espanha.

O questionário foi composto de questões relacionadas à experiência em projeto de Experience Design, o significado dessa modalidade de projeto, as características, as competências e competências do designer, exemplos de projetos já desenvolvidos, as tendências em trabalhos futuros e preferências de atuação, como descritas no Quadro 2.

Quadro 2 - Questões do questionário aplicado em inglês (como aplicado) e em português

1. Have you worked on experience design projects before?

1. Você já trabalhou com Experience Design?

2. What does experience design mean to you?

2. O que Experience Design significa para você?

3. What are the things that you must do for a project be considered as experience design?

3. Quais as características você acredita ser indispensável para um projeto ser considerado Experience Design?

4. What are the essentiall skills/understandings that designers require to realize projects in this area?

4. Quais competências e conhecimentos de designers são essenciais para realizar um projeto nessa área?

5. Could you name some important projects which you have worked on? Please attach references/images/presentations if available

5. Você poderia citar algum projeto importante que você tenha trabalhado?

Por favor, anexar referências/imagens/apresentações se possível

6. What were the various experiences created for the customers in these projects? And what were the benefits of these experiences? Support with images if possible

6. Quais foram as várias experiências criadas para aos usuários desses projetos? E quais foram os benefícios dessas experiências? Se possível, complemente com imagens

7. What are the kind of experience design projects you would like to work on in the future? Explain in detail

7. Com quais tipos de projetos de Experience Design você gostaria de trabalhar no futuro? Explique com detalhes

Fonte: Elaborado pelo autor, com base na pesquisa realizada (2012) 
Optou-se por retratar nesse artigo os resultados das perguntas 3, 4 e 5 por julgar essas como sendo as questões que melhor sintetizam e representam a problemática proposta nessa pesquisa.

Nas respostas atribuídas a pergunta 3 "Quais as características você acredita ser indispensável para um projeto ser considerado Experience Design?" todos os entrevistados citaram a preocupação com o usuário e com o entendimento das necessidades desse com uma importante etapa no processo de projetar uma experiência. Porém para, além disso, é possível perceber que outros atributos inéditos são citados com importantes para essa abordagem projetual, como por exemplo:

- "conectar os usuários ao projeto" (não trata apenas da interação momentânea é algo que cria conexão, e, portanto, atribui significado a longo prazo);

- "criar uma visão compartilhada - cliente x usuário" (criar uma visão compartilhada significa construir junto e só é possível construir algo junto se existir respeito e tolerância);

- "entender o que os torna feliz";

- "entender as conotações futuras e emoções derivados de cada um dos aspectos do projeto" (preocupação com a felicidade ou com os impactos emocionais futuros são aspectos pouco comuns quando tratamos de parâmetros e indicadores mencionados nas pesquisas de design);

- "criar excitação, curiosidade" (em inúmeros projetos os designers tentam resolver o "problema" da excitação e da curiosidade entregando produtos claros e objetivos na busca de "facilitar" o dia-a-dia dos usuários, nesse exemplo citado anteriormente o entrevistado cita que o projeto para experiência deve criar excitação e curiosidade).

Todos esses aspectos identificados na Figura 1 podem ser considerados atributos do projeto para experiência, pois apesar de possuir elementos comuns a qualquer outra abordagem de design, também agregam outras características.

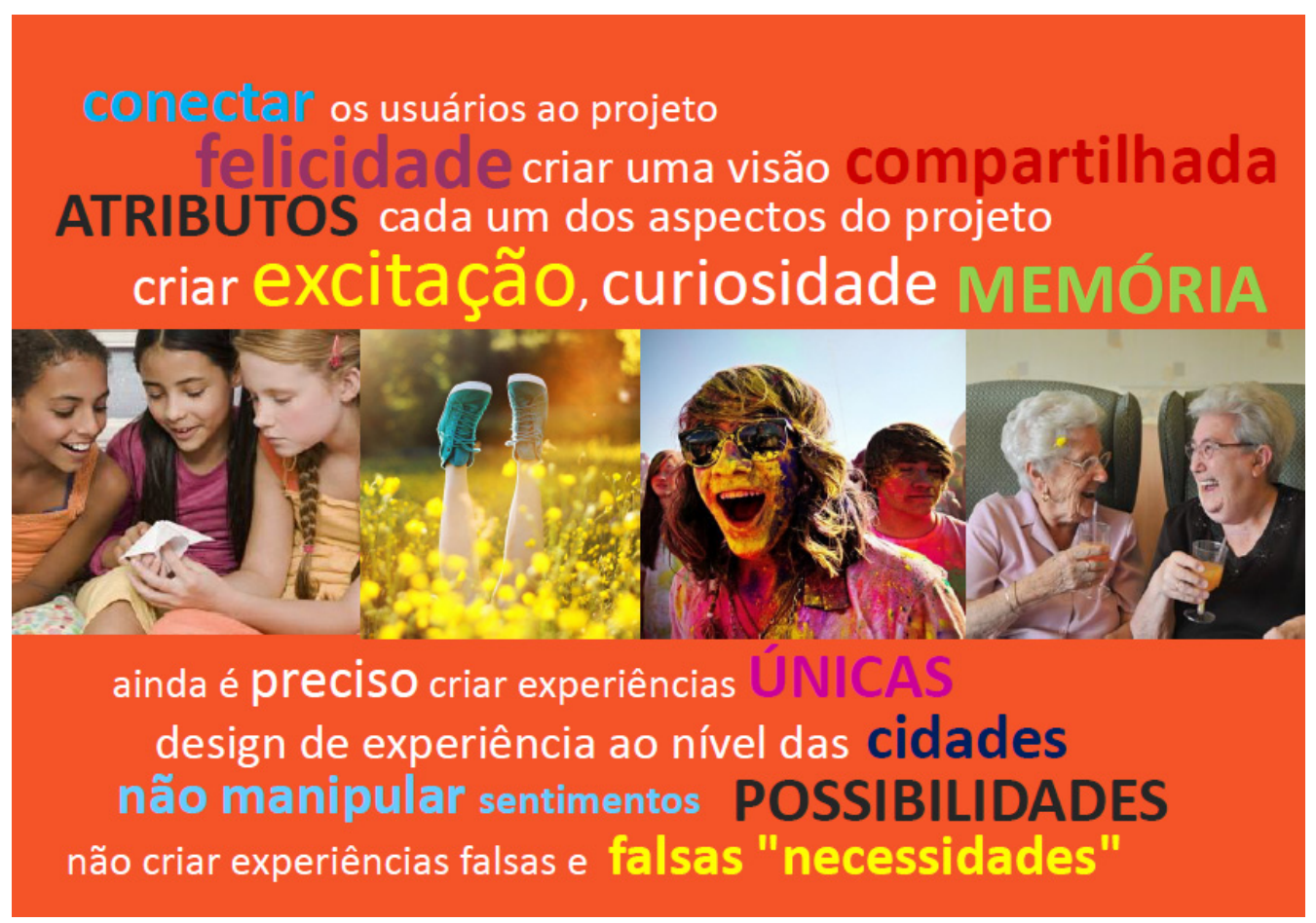

Figura 1 - Atributos que o design para experiência deve despertar

Fonte: Elaborado pelo autor, com base na pesquisa realizada (RIBEIRO, 2012) 
A análise dos "discursos" dos entrevistados, essas por sua vez, nos faz olhar o design para experiência como algo que caminha em direção a uma nova abordagem, composta por elementos que combinam atributos da experiência projetual "tradicional", mas também agregam novos, como os citados acima (felicidade, conexão, excitação, curiosidade). Como citado por Pine \& Gilmore (2009) na introdução dessa pesquisa, essas novas abordagens emergem, na tentativa de alinhar o design ao comportamento social contemporâneo e suas novas implicações.

A pergunta 4 do questionário diz respeito às competências e conhecimentos dos designers essenciais para realização de um projeto de experiências. Entre as respostas coletadas, três chamaram atenção por fugirem um pouco do padrão de características comumente atribuídos aos designers de modo geral, possibilitando-nos entender com maior profundidade quais aptidões específicas, porém não exclusivas aos designers, são ativadas nesse processo:

- Entrevistado 1: "Designers que têm uma perspectiva ampla de vida (...). Um designer que possa fazer uso das suas habilidades espaciais, visuais, verbais, habilidades sócio-psicológicas e analíticas de uma só vez."

- Entrevistado 2: "Eles não devem ser rígidos (...) devem possuir empatia."

- Entrevistado 4: "Compreensão emocional"

Essas características ativam capacidades que vão além dos formatos disciplinares do design e das competências consideradas nos métodos de design em geral e no mercado de trabalho. São aspectos ainda pouco explorados dentro do universo do design, como no caso das habilidades ligadas a aspectos intuitivos e emocionais que são construídas, antes de qualquer coisa, através da vivência humana subjetiva. Esses atributos relacionados aos designers de experiência somam à atividade projetual atual, novas competências e novas possibilidades relacionadas às metodologias já existentes.

As imagens a seguir (FIG. 2 a 5) exemplificam alguns dos projetos citados pelos entrevistados, na pergunta 5 "Você poderia citar algum projeto importante que você tenha trabalhado? Por favor, anexar referências/imagens/apresentações se possivel".
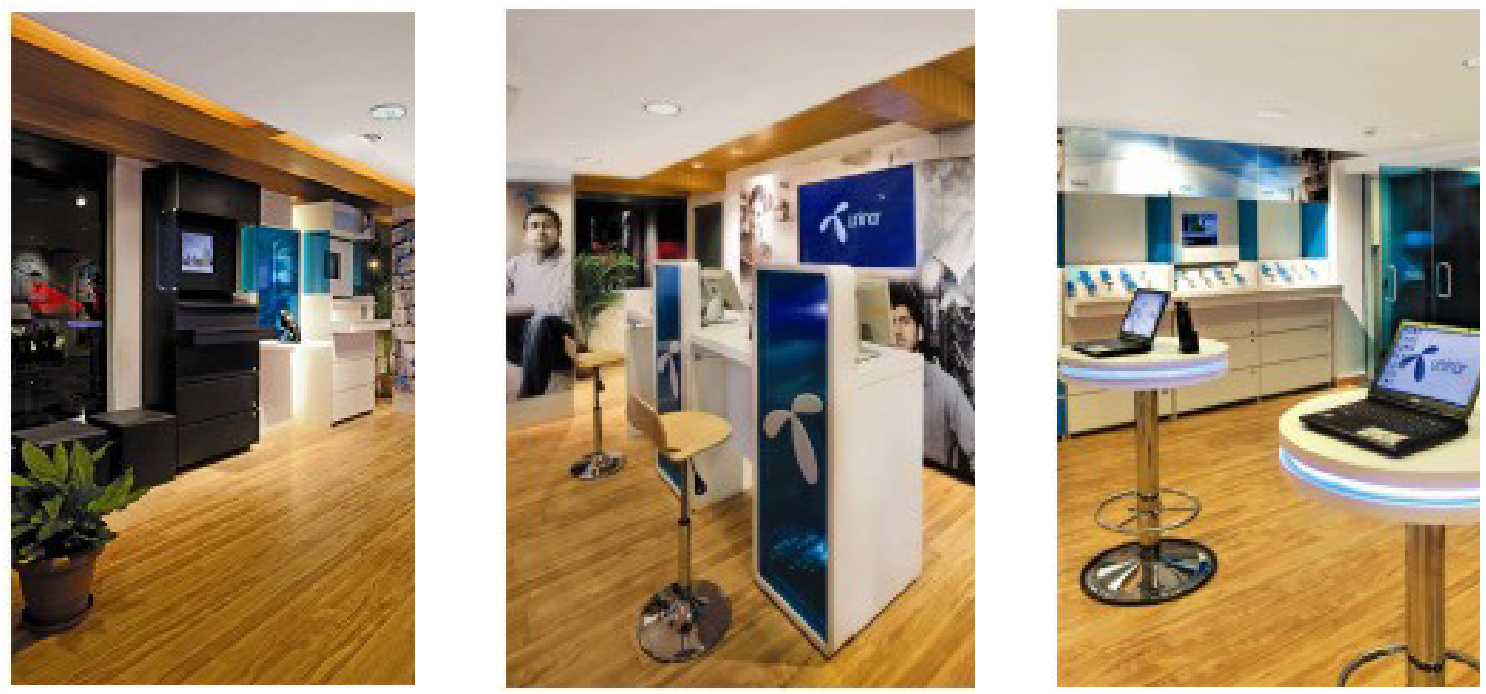

Figura 2 - Projeto Uninor: Ioja Telecom $\left(120 \mathrm{~m}^{2}\right)$ do Entrevistado 1 

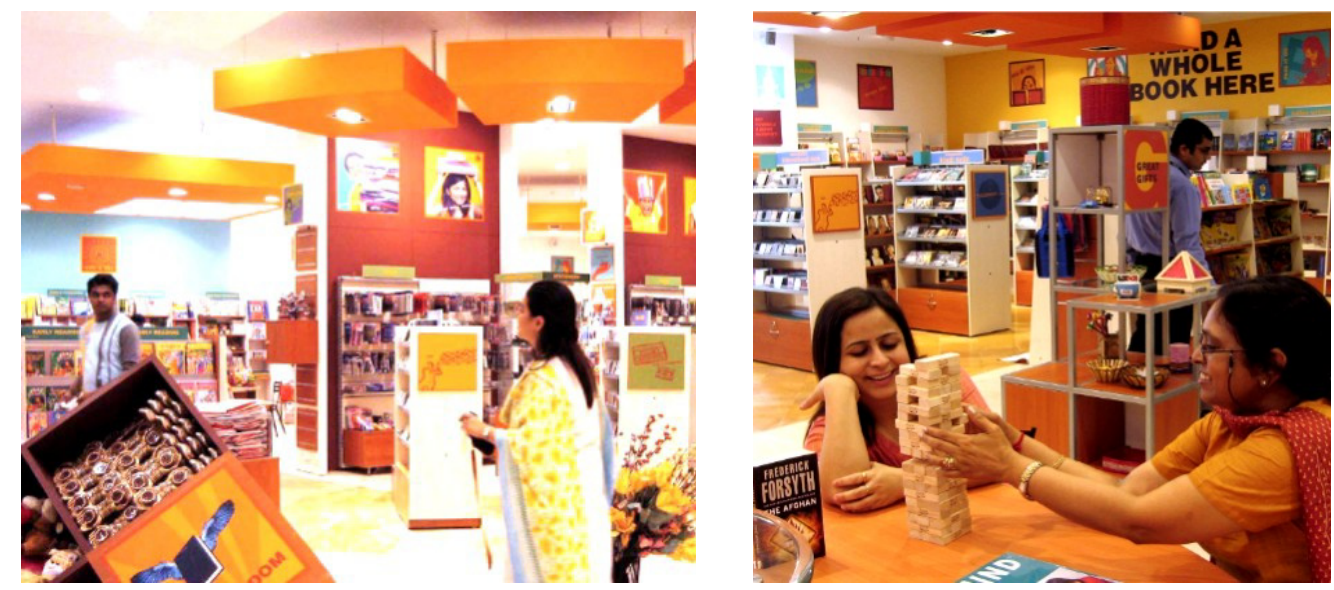

Figura 3 - Projeto Depot: loja de livros de música para presente $\left(300 \mathrm{~m}^{2}\right)$ do Entrevistado 1

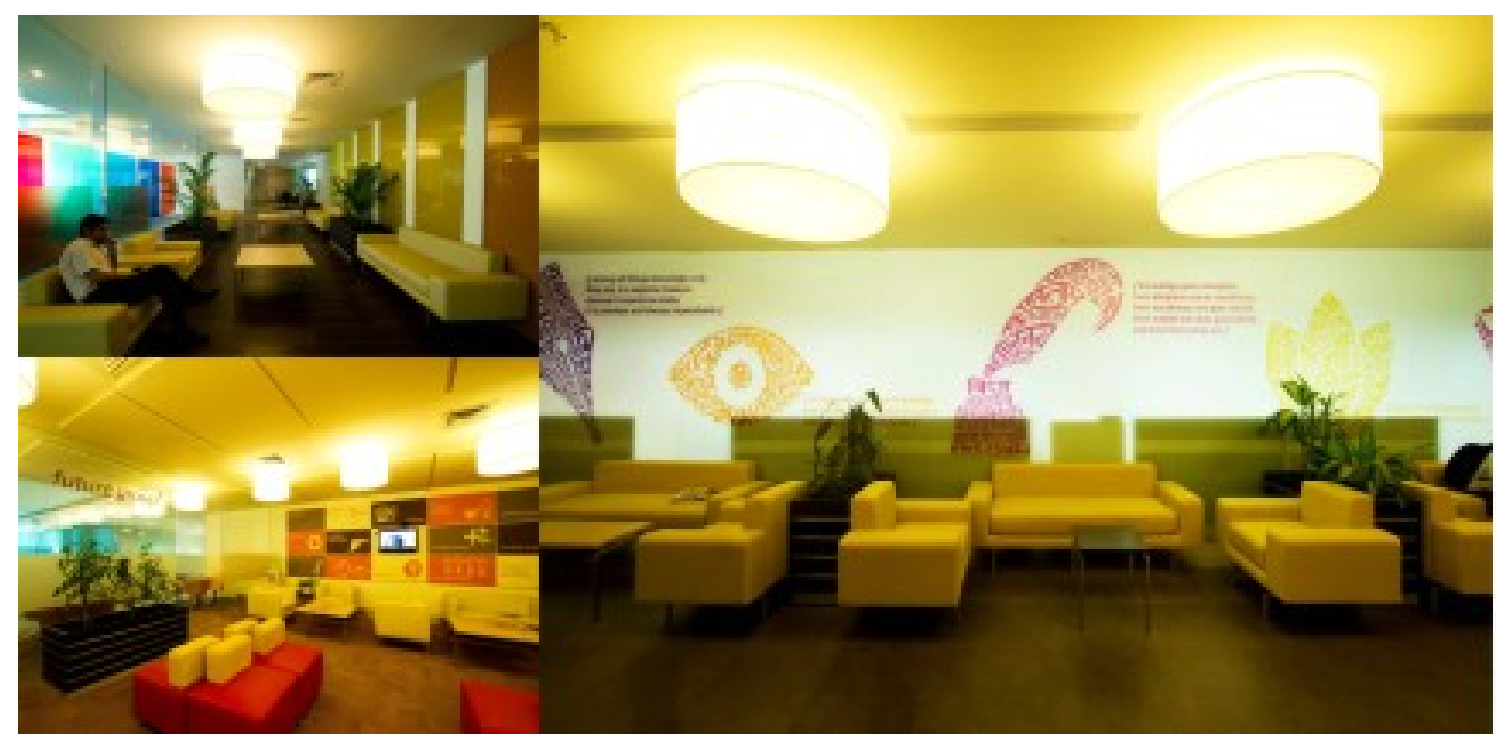

Figura 4 - Future Retail Home Office: escritório corporativo $\left(18.000 \mathrm{~m}^{2}\right)$ do Entrevistado 1
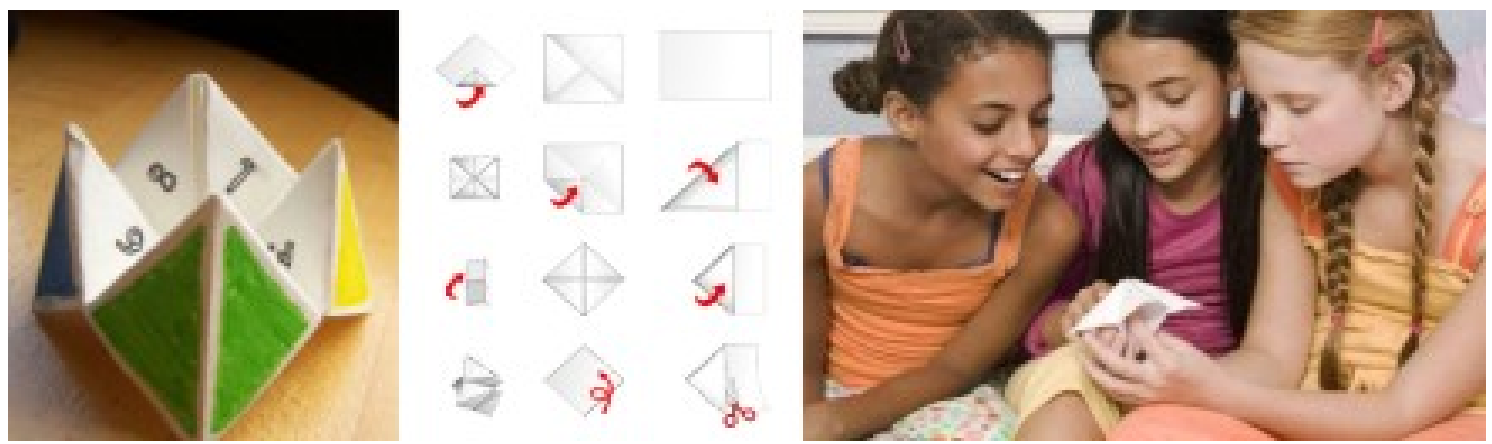

Figura 5 - Flyer da Prajna Educational Trust do Entrevistado 5

Depois de revisada a literatura acerca do design para a experiência, e realizadas entrevistas a respeito dos atributos e características dos projetos nessa área, constatou-se que há uma série de possibilidades para a atuação dos designers nessa 
área. Isso demonstra que essa é uma abordagem ampla e que não existe apenas um caminho para se atuar no campo das experiências, mas sim, uma infinidade de possibilidades, que nos convidam ao desafio de vivenciar novas abordagens projetuais. Talvez sejam interessantes novas experiências de atuação interdisciplinar com profissionais de outras áreas, uma vez que essa área requer competências das mais diversas. Porém para tanto é preciso quebrar barreiras e vislumbrar novos horizontes, pois como disse Rafael Cardoso:

À medida que a produção industrial vai se tornando cada vez mais precisa e diferenciada, é no âmbito eminentemente subjetivo da experiência e da emoção que as verdadeiras decisões de projeto deverão se dar (CARDOSO, 2008, p. 236).

Portanto é preciso olhar para essa mudança dinâmica como uma oportunidade e ao mesmo tempo um desafio. Oportunidade de construir um futuro diferente, mas humano e mais preenchido de significados e valores, deixando de lado as preocupações em dar nomes e segmentar as infinitas divisões de áreas criadas diariamente. Desafio porque romper velhos paradigmas e dogmas da sociedade é uma complexa atividade, principalmente quando estamos tratando de padrões que beneficiam grupos específicos, muitas vezes minoritários, que estão em busca da satisfação de interesses individuais, que muitas vezes pouco tem a ver com as demandas mais urgentes da sociedade.

\section{CONSIDERAÇÕES FINAIS}

Esses desafios enfrentados pelas novas experiências projetuais que emergem no cenário mundial, nos oferecem um oportunidade singular e evidencia a real importância da atuação interdisciplinar dos designers, uma vez que essa área requer competências das mais diversas. Para tanto é preciso quebrar barreiras e vislumbrar novos horizontes, pois cada vez mais é latente a crescente necessidade de se buscar soluções projetuais no âmbito eminentemente subjetivo da experiência e da emoção, se quisermos buscar soluções mais adequadas aos novos contextos globais e mais singulares do ponto de vista cultural, social, ambiental e econômico.

Novas possibilidades de atuação no campo do design para a experiência se fazem cada vez mais reais, tendo em vista a mudança dinâmica global que carrega em si uma oportunidade de construir um futuro diferente, mas humano e mais preenchido de significados e valores. Contudo a atuação nessa área é também um grande desafio, porque romper velhos paradigmas e dogmas da sociedade é uma complexa atividade, principalmente quando estamos tratando de pessoas, pois pessoas são vidas, sem as quais nenhum projeto seria possível.

Apesar disso, leque vasto de possibilidades de atuação na área do experience design está posto aos designers interessados. Como demonstrado nas entrevistas realizadas durante a pesquisa, as oportunidades vão desde projetos de interior de carros até jogos infantis. Com isso podemos concluir que o design para a experiência é algo abrangente e complexo, e que apresenta aos designers possibilidades impares de atuação nas mais diversas áreas e setores. Além de contribuir para o avanço frente as crises enfrentadas pela sociedade atual carente de projetos que inaugurem novas bases para o exercício da profissão nas próximas décadas. 
É possível perceber o valor da pesquisa buscando aprofundar conhecimentos, discutir e refletir sobre o que está estabelecido e o que estar por vir, contribuindo de forma significativa para a construção de sujeitos mais críticos e autônomos.

Como mostrado na etapa das entrevistas, existe uma preocupação, por parte dos designers, em fazer algo novo e com novas abordagens projetuais. Na posição de pesquisadora com um olhar estrangeiro, um olhar de alguém que vem de outro contexto cultural, foi possível notar que para o contexto indiano esses projetos estão dando um salto quântico com relação ao cenário no qual eles estão inseridos.

Portanto é indispensável dizer que todo projeto de design, em especial os de experiência, está diretamente associado ao contexto socioeconômico/cultural/político e aos usuários relacionados. A ausência desses dois aspectos torna impossível a compreensão e análise dos projetos e consecutivamente entendimento desses.

Por fim, espera-se que com esse trabalho inspire novas pesquisas e incentive a criação de projetos que não se restrinjam ao projeto de um objeto, lugar ou serviço, mas, sobretudo, o desenho de contextos ambientais e culturais apto ao florescimento de experiências humanas singulares e significativas.

\section{REFERÊNCIAS}

FERREIRA, A. B. H. Novo dicionário da língua portuguesa. 2a Ed. Rio de Janeiro: Nova Fronteira, 1986.

BONDÍA, J. L. Notas sobre a experiência e o saber de experiência. Universidade de Barcelona, Espanha. Tradução de João Wanderley Geraldi. Universidade Estadual de Campinas, Departamento de Lingüística, 2002.

BENJAMIN, W. Experiência e pobreza. In: Magia e técnica, arte e política: ensaios sobre a literatura e história da cultura, obras escolhidas. São Paulo: Brasiliense: 1987.

CARDOSO, Rafael. Uma Introdução à História do Design. São Paulo: Blucher, 2008.

CINTRA, A. M. M. Determinação do tema de pesquisa. In: Ciência da Informação, Brasília - DF, v. 11, n. 2, p. 13-16, 1982.

FLORIDA, R. L. A ascensão da classe criativa. Tradução de Ana Luiza Lopes. Porto Alegre: L\&PM, 2011.

GOODE, Willian J. \& HATT, Paul K. Métodos em pesquisa social. São Paulo: Nacional, 1977.

JAY, Martin. Cantos de experiência: variaciones modernas sobre un tema universal. Buenos Aires: Paidós, 2009.

MORESCO, Tiago. As múltiplas faces de uma experiência. 2011. Disponível em http://www.designdeexperiencia.com.br/as-multiplas-faces-de-uma-experiencia/. Acessado em Setembro de 2012.

NOVAK, Aldo. O segredo para realizar seus sonhos. Rio de Janeiro: Ediouro, 2008.

NARDELLI, N. C. Design para a experiência e o uso das tecnologias de informação e comunicação. Universidade de São Paulo. Pós-Graduação em Arquitetura e Urbanismo, Escola de Engenharia de São Carlos. Dissertação de Mestrado, 2007.

PONDÉ, L.F. Guia Politicamente Incorreto da Filosofia. São Paulo: Leya Brasil, 2012. 
PRESS, M., COOPER, R. El diseño como experiencia: el papel del diseño y los diseñadores em el siglo XXI. Barcelona: GG Diseño, 2009.

RIBEIRO, Ana Carolina Assis. Design para a experiência: atributos e possibilidades. 2012. 62 f. Monografia (Projeto de Graduação apresentado ao Curso de Design de Produto) - Escola de Design da Universidade do Estado de Minas Gerais, Belo Horizonte, 2012.

RICHARDSON, R. J. Pesquisa social: métodos e técnicas; colaboradores José Augusto de Souza Peres (et AL.). São Paulo: Atlas, 1985.

SEVERINO, A. J. Metodologia do trabalho científico. Ed. São Paulo: Cortez, 1993.

SCHNEIDER, B. Design - uma introdução: o design no contexto social, cultural e econômico. Tradução Sonali Bertuol, George Bernard Sperber. São Paulo: Blucher, 2010. 